УДК $81^{\prime}$

DOI: 10.33184/YVDK-2021-04-30.8

Р.3. Мурясов (проф. БашГУ, г. Уфа)

\title{
СТРУКТУРА МЕСТОИМЕНИЙ
}

В анализируемых языках (латинском, русском, английском, немечком, франиузском, башкирском и татарском) представлены три типа основ местоимений: простые, сложные и составные. Не все структурные типы в равной степени свойственны разным разрядам. Простые характерны для личных местоимений, а составные и сложные - для неопределенных.

Ключевые слова: структура, простые, сложные и составные местоименные основы, разряды местоимений.

The analyzed languages (Latin, Russian, English, German, French, Bashkir, and Tatar) present three types of pronoun bases: simple, complex, and compound. Not all structural types are equally characteristic of different categories. Simple ones are characteristic of personal pronouns, while compound and complex ones are characteristic of indefinite ones.

Keywords: structure, simple, complex and compound pronominal bases, categories of pronouns.

В данной статье речь идет о морфологической структуре разных разрядов местоимений.

Простые (непроизводные) местоимения. Ядро данной группы в сравниваемых нами языках составляют личные местоимения.

Структура местоимений в разных языках имеет свои специфические особенности. Обычно в одном и том же языке различные типы основ имеют неодинаковый удельный вес в разных лексико-грамматических разрядах. Нередко в рамках одного и того же разряда выделяются как простые, так и сложные 
и составные структуры. Особенно богатым набором структур обладают во всех языках неопределенные местоимения (pronomina indefinita).

русск. Рядом с Маргаритой никого не было, но немного подальше за кустами слышались всплески и фырканье, там тоже кто-то купался (Булгаков);

нем. In ihrer Nähe war niemand, aber in einiger Entfernung hörte sie hinter den Büschen ein Plätschern und Prusten - dort badete auch wer $(\approx$ jemand irgendwer, irgendjemand $)$;

фp. Près de Marguerite, il n'y avait personne, mais plus loin, derrière les baisson, il devait y avoir un autre baigneur, car, on enlenotent quelqu'on s'ébrouer et éclabousser.

В латинском языке доминируют простые и сложные местоименные основы [1]: простые: личные (ego «я», tu «ты», nos «мы»), притяжательные (meus «мой», tuus «твой» и т.п., указательные (hic «этот», is «тот, он», idem «тот, же, он, один и тот же и т.п.), вопросительные (quis ${ }^{1}$, «кто», quid ${ }^{1}$ «что», qui ${ }^{1}$ «кто, который, какой, что за» и т.п.), некоторые неопределенные местоимения (quis ${ }^{2}$ «кто-нибудь, какой-нибудь», пето «никто», nihil «ничто»); сложные: относительные (qui-cunque «всякий кто, все что, кто бы ни, что бы ни», quis-quis «всякий кто, кто бы ни» quid-quid «все что, что бы ни»), неопределенные: aliquis, alique, aliquam «кто-нибудь, какой-нибудь», quidam, quedam, quiddam, quoddam, quispiam, quisque, quaque, quique «кто-то, какой-то, некоторый, один), unisquisque, unaquaque, unumquidque, unumquodque, quilibet, quidlibet, quodlibet, quivis «каждый, всякий», uterque «каждый из двух, и тот и другой», neuter «никто из двух, ни тот ни другой».

Для русского языка также характерны простые и сложные структуры местоименных основ: простые: личные (я, ты, он, мы), притяжательные (мой, твой, его, наш, ваш, их), вопросительные (кто? что? чей? который?), относительные, совпадающие с вопросительными, определительные (весь, всякий, каждый, любой, иной, сам и т.п.); сложные: некоторые указательные (тотто, такой-то), отрицательные (никто, не́кого, ничто, не́чего), неопределенные (кто-нибудь, кто-то, кто-либо, кое-кто, некто, что-то, что-нибудь, что-либо, кое-что, нечто).

В местоимениях английского языка также доминируют простые и сложные структуры [3]; лишь в определенных случаях 
встречаются составные основы: простые: личные (I, me, you, we, they), притяжательные (mу «мой», his «его», her «её», its «его», our «наш» и т.п.); указательные (this «это», that «то», it «это», one ${ }^{2}$ «тот, этот»), вопросительные и относительные (who «кто», whose «чей», what «что», which «который»); безличное $\mathrm{it}^{2}$, некоторые неопределенные (some «какой-нибудь, какой-то», all «все»; any «что-нибудь, кто-нибудь», none «никто, ни один», much «много», many «много», little «мало», few «немного, немногие», both «и тот, и другой», either «любой», each «каждый», other «другой», one $^{1}$ ); сложные: возвратные (myself, yourself, himself, ourselves, themselves, oneself «себя, себе, собой»); неопределенные (anybody «кто-нибудь, что-нибудь», somebody «кто-то, кое-кто», everybody «каждый, всякий"); составные: взаимные (each other / one another «друг друга»).

В немецком языке представлены два вида местоименных основ [4,5]: простые: личные, притяжательные ich-mein, du-dein, wir-unser и т.п.), часть указательных местоимений $\left(\operatorname{der}^{1}\right.$ «этот», es ${ }^{2}$ «это», dieser «Этот», jener «тот», solcher «такой, подобный», selber «сам», selbst «сам», beide «тот, и другой, оба»), вопросительные (wer ${ }^{1}$ «кто», was ${ }^{1}$ «что», welcher ${ }^{2}$ «который», wer ${ }^{2}$ «кто», was ${ }^{2}$ «что»), возвратное (sich / mich / dich / uns / euch); некоторые неопределенно-личные (man, ein, einer «1. кто-то, кто-нибудь, ктолибо», jeder «каждый», jemand «кто-нибудь, кто-либо», etwas «что-нибудь, кое-какие, некоторые, какие-нибудь, кое-кто, коечто»), отрицательные (niemand «никто», nichts «ничто», kein «не»), сложные: часть указательных (derjenige «тот», derselbe «тот же, тот самый»). Взаимное местоимение einander «друг друга», jedermann «всякий, каждый»), составные вопросительные местоимения: was für ein? «который», неопределенное (so etwas «нечто подобное»).

Наиболее сложная картина выявляется при анализе структуры местоимений во французском языке [6, 7]. В нем доминируют сложные и составные типы основ: простые: приглагольные и автономные личные местоимения (tu, ill, elle, nous, vous; moi, toi, lui, soi и т.п.), указательные се «это, то»), некоторые вопросительные qui ${ }^{1}$ «кто», que ${ }^{1}$ «что», quoi «что»), немногие относительные (qui ${ }^{2}$ «который», que ${ }^{2}$ «которого, которую, которых», don't «которого, которой, которых»), безличное местоимение (il ${ }^{2}$ : il pleut «идет дождь», il est trois heures 
«время три часа»); отрицательные (nul «никто», personne «никто», rien «ничто, ничего»); неопределенные (un «один», tout «все», certains «некоторые» и т.п.), (un autre «какой-нибудь другой», autre chose «что-нибудь другое», qui que «кто бы ни», quoi que «что бы ни»; сложные вопросительные (lequel ${ }^{1}$ «который», laquelle $^{1}$ «которая», lesquelles «которые и т.п.), относительные (aucun «никто, никакой, ни один»), составные (de laquelle «которой», à laquelle «которой»); неопределенные (l'autre quelqu'on «кто-нибудь, кто-то», d'autres «какие-нибудь другие», quelques «кто-нибудь, кто-то, d'autres «какие-нибудь другие», quelques-uns «некоторые», quiconque «всякий кто»; указательные (celui-la «тот», celle-ci «эта» celle-la «та», (le même «тот же самый», la те̂те «та же самая»); составные: притяжательные (le mien «мой», la mienne «моя», le tien «твой», la tienne «твоя», les nôtres «наш», les vôtres «ваш», les leurs «их»).

Во французском языке целые фразы функционируют в качестве местоимений, ср. qui est-ce qui? «кто?», qu'est-ce qui?, qu'est-ce que? «что?».

В тюркских (башкирском, татарском) языках структура местоимений имеет ряд особенностей, не присущих и.-е. языкам. Общим с и.-е. языками является наличие непроизводной структуры личных местоимений: башк. мин «я», һин «ты», ул «он», безु «мы», hез̧ «вы», улар «они»; тат. соответственно: мин, син, ул, без, сез, алар.

Несколько отличную трактовку в башкирском и татарском языках получили притяжательные местоимения. В башкирском языкознании представлена точка зрения, согласно которой притяжательные местоимения образуются от личных местоимений с помощью суффиксов -ныкы /-неке, быкы / беке / дыкы / -деке (мин «я» - минеке «мой / моя / моё», без «мы» беззеке «наш, наша, наше» и т.п.) [8], в то время как в ТГ отмечается, что принадлежность выражается формами генитива личных местоимений (минем «мой», синең «твой», безнең «наш», сезнең «ваш» и т.п. и путем присоединения к личным местоимениям аффиксов -ныкы

-неке, ср. минем китап «моя книга» и китап минеке «книга моя» [9]; указательные местоимения: простые (был «это», теге «тот», шул «тот», ошо «это самое» и т.п.), аффикальные (бындай «такой», тегендәй, шундай, ундай «этакий», былай «эдак» и т.п.); 
вопросительные: простые (кем «кто», ни «что», нимә «что» и т.п.), аффиксальные: (кайз̧а «где, куда», күпме «сколько» и т.п.); отрицательные: простые (һис «ничто, несколько», бер «один, нечто»), составные (һис нәмә «ничто», һис ниндәй «никакой», һис нисек «никоим образом», бер нәмә «нисколько», бер нимә лә / бер нимә «ничто», бер кем дә «никто», бер нимә / бер нимә лә «ничто» и т.п.), неопределенные местоимения, в основном имеют составные структуры (әллә кем «кто-то», әллә нимә «что-то», әллә ниндәй «какой-то», әллә нисек «как-то», әллә кайз̧а «где-то», әллә нисә «неизвестно сколько», кайһы бер «некоторые», теләһә кем «кто хочет, хоть кто», теләһә касан «хоть когда» и т.п.); определительные: простые (hәр «каждый» Үз «сам»), производные, имеющие варианты (бөтә, бөтәһе «весь»; бары, барлык, барлығы «весь»; һәммә «весь»), составные, имеющие простые варианты (hәр, hәр кем «каждый», hәр бер «каждый»).

В татарском языке структура многих местоимений сходна с местоимениями в башкирском языке, с учетом фонологических особенностей этих двух языков. В некоторых разрядах татарских местоимений имеются также единицы, которые в башкирском языке не представлены указательные местоимения, ср. тат. әнә «вон», менә «вот», биредәге «здешний, находящийся здесь»; в татарском в структурном отношении выделяются три типа неопределенных местоимений: производные с помощью аффиксов -ыр/-ер, -дыр/-дер, которые имеют варианты в составных структурах (кемдер / әллә кем «кто-то», нәрсәдер/ әллә нәрсә /нидер /әллә ни «что-то», ниндидер /әллә нинди «какой-то», ничектер / әллә ничек «как-то», кайдадыр / әллә кайда «где-то» и т.п.); сложные (кайбер «некоторые», берничә / беркадәр / берникадәр «несколько» и т.п.). Единичной структурной особенностью обладает местоимение фәлән «некий, такой-то».

\section{ЛИТ ЕРАТУРА}

1. Соболевский С.И. Грамматика латинского языка. Санкт-Петербург, 1998.

2. Валгина Н.С., Розенталь Д.Э., Фомина М.И., Цапукевич В.В. Современный русский язык. М.: Изд-во «Высшая школа», 1966.

3. Камянова Т.Г. English grammar. M., 2015. 
4. Duden. Bd. 4. Die Grammatik, Dudenverlag. Mannheim. Leipzig. Wien. Zürich, 2005.

5. Helbig G., Buscha J. Deutsche Grammatik. Langenscheidt. Verlag Enzyklopädie. Leipzig. Berlin. München. Wien. Zürich. New York, 1996.

6. Dictionnaire de linguistique. Librairie Larousse. Paris, 1973.

7. Гак В.Г., Ганшина К.А. Новый французско-русский словарь. М.: Изд-во «Русский язык», 1999.

8. Грамматика современного башкирского литературного языка. М.: Изд-во «Наука», 1981.

9. Татарская грамматика. Т. II. Морфология. Казань, 1997.

\section{Художественная литература}

1. Булгаков М.А. Мастер и Маргарита. М., 1973.

2. Bulgakov M. The Master and Margarita. The Harvill Press. London, 1996.

3. Bulgakow M. Der Meister und Margarita. AufbauVerlag. Berlin und Weimar, 1983.

4. Boulgakov M. Le Maître et Marguerite. Paris, 2005.

(C) Мурясов P.3., 2021 г. 